response studies in healthy men Arteriosclerosis Thrombosis 1991;11:429-35.

117 Hakkert BC, Kuijpers TW, Leeuwenberg JFM, van Mourik JA, Roos D. Neutrophil and monocyte adherence to and migration across monolayers of cytokineactivated endothelial cells: The contribution of CD18, ELAM-1, and VLA-4. Blood 1991;78:2721-6.

118 Butcher EC. Leucocyte-endothelial cell recognition: Three (or more) steps to specificity and diversity. Cell 1991;67:1033-6.

119 Adams DO, Hamilton TA. Macrophages as destructive cells in host defense. In: Gallin JI, Goldstein IM, Snyderman $\mathrm{R}$, eds. Inflammation: Basic principles and clinical correlates, second edition. New York: Raven Press, clinical correla

120 Brown MS, Goldstein JL. Lipoprotein metabolism in the macrophage: implications for cholesterol deposition in atherosclerosis. Ann Rev Biochem 1983;52:223-61.

121 McMillan GC, Duff GL. Mitotic activity in the aortic lesions of experimental atherosclerosis in rabbits. Arch Pathol 1948;46:179-82.
Pesions of experimental

122 Benditt EP, Benditt JM. Evidence for a monoclonal origin of human atherosclerotic plaques. Proc Natl Acad Sci USA 1973;70:1753-6.

123 Rosenfeld ME, Ross R. Macrophage and smooth muscle cell proliferation in atherosclerotic lesions of WHHL and comparably hypercholesterolemic fat-fed rabbits. Arteriosclerosis 1990;10:680-7.

124 Gordon D, Reidy MA, Benditt EP, Schwartz SM. Cell proliferation in human coronary arteries. Proc Natl Acad Sci USA 1990;87:4600-4.

\title{
ABSTRACTS IN CARDIOLOGY
}

\section{Laboratory screening}

Laboratories that estimate plasma lipid concentrations serve two purposes. One function is to screen large numbers of symptom free individuals, the other to provide detailed lipid profiles on those who already have clinically expressed atherosclerosis. The survey of United Kingdom laboratories reported in the fournal of Clinical Pathology shows little evidence that the service provided is being tailored to these separate functions.

A pragmatic approach to symptom free individuals is the estimation of total serum cholesterol in the non-fasting state. The assumption that cholesterol concentrations less than $6.5 \mathrm{mmol} / \mathrm{l}$ are acceptable will miss few important atherogenic lipid abnormalities. Concentrations above $6.5 \mathrm{mmol} / 1$ and individuals with symptoms as defined above, require fasting samples and the additional measurement of triglyceride and HDL cholesterol. The survey, however, showed that half the laboratories still demanded fasting samples before undertaking any lipid analysis whatsoever.

The technical standard of the laboratories in estimating serum total cholesterol was high, though interlaboratory variation may still be too large. This reflects considerable diversity in calibration procedures. Many laboratories $(62 \%)$ continue to give gratuitous advice on the significance of the result. A reference range based on estimations of lipid concentrations in supposedly normal individuals is meaningless, given the high serum cholesterol concentration in United Kingdom populations and the prevalence of occult atherosclerotic disease. Giving a value above which there is a risk of ischaemic heart disease is arbitrary because the risk is a continuous variable.

The provision of more sophisticated lipid analysis including $L p(a)$ and apolipoproteins is far more variable, the quality of the analysis less controlled, and the clinical significance of any abnormality found in relation to treatment less certain.

Whatever the pros and cons of treating hyperlipidaemia in symptom free individuals by anything more than dietary advice, an increasing number of individuals wish to know their cholesterol concentration. This tendency will be accelerated by the over-thecounter testing kits that are now available. Their accuracy is not certain and they are not subject to formal quality assurance when used by the population at large.

Doctors requesting lipid analysis should make clear what level of sophistication they need to manage their patients clinically. Laboratories should be prepared to accommodate these needs.

MJ DAVIES

\section{Laboratory facilities for investigating lipid disorders in the United Kingdom: results of the British Hyperlipidaemia Association Survey}

\section{F Laker, I P D Reckless, D I Betteridge, PN Durrington, I P Mäller, D P Nicholls, I Shepherd,} $G R$ Thompson

\section{Abstract}

Aims.-To determine the availability of facilities for the investigation of hyperlipidaemia in the United Kingdom.

Methods-A questionnaire was sent to all health districts in the United Kingdom.

Results. - The response rate was $81 \%$. All laboratories used enzymatic techniques to measure serum triglyceride and cholesterol concentrations, although there were differences in standardisation procedures. Reference ranges for serum lipids were quoted by $58 \%$ of laboratories while $50 \%$ quoted "desirable limits". Almost half specified that fasting blood samples were required. High density lipoprotein cholesterol concentrations were estimated by $75 \%$ and apolipoproteins AI and B by $14 \%$ of laboratories; there were differences in specimen type and considerable diversity in procedures used for measurement.

Conclusions.-Many laboratories were unaware of current recommendations for screening for hypercholesterolaemia in the community. The present survey indicated an urgent need for the introduction of better reference methods, standardisation, and quality assurance procedures before apolipoproteins become a routine part of coronary heart disease risk assessment. $¥$ Clin Pathol 1992;45:102-5.) 